\section{Molecular Syndromology}

Mol Syndromol 2018;9:171-174

DOI: $10.1159 / 000490845$
Accepted: June 11, 2018

by M. Schmid

Published online: July 13, 2018

\title{
Syndromes Hidden within the 16p11.2 Deletion Region
}

Copy number variations (CNVs) are a form of structural genome variations by which a stretch of chromatin between 2 breakpoints on the same chromosome arm is either lost or duplicated. CNVs larger than $100 \mathrm{~kb}$ arise de novo in the general population at an estimated rate of about $1.2 \times 10^{-2} \mathrm{CNV}$ s per meiosis [Itsara et al., 2010]. In roughly $14-18 \%$ of the children with developmental delay, a CNV larger than $400 \mathrm{~kb}$ may be phenotypically significant [Cooper et al., 2011; Hochstenbach et al., 2011]. CNVs occur more frequently than germline single nucleotide variations (SNVs), and they affect more nucleotides than SNVs [Stankiewicz and Lupski, 2010; Campbell and Eichler, 2013]. CNVs may either be flanked by unique DNA sequences or by segmental duplications. While the first occur spontaneously and are unique in size and breakpoint positions, the second type of CNVs are recurrent and of a fixed size. The segmental duplications flanking recurrent CNVs are remnants of chromosomal evolution, which render their loci inherently instable [Eichler et al., 2001; Samonte and Eichler, 2002; Bailey and Eichler, 2006].

Although recurrent CNVs occur at higher frequency in patient cohorts than in the general population, some were found in both children with developmental disorders and their healthy parents [Girirrajan et al., 2010; Poot et al., 2010]. This poses particular challenges in gauging their potential phenotypic effects. Girirajan and

\section{KARGER}

๑ 2018 S. Karger AG, Basel
Eichler [2010] proposed that such CNVs may interact with additional rare de novo or transmitted alleles to cause complex genetic disorders. Such a constellation may apply to some families of children with autism spectrum disorder (ASD) [Bucan et al., 2009; Salyakina et al., 2011; van Daalen et al., 2011; Poot, 2013]. Alternatively, an inherited or de novo deletion on one chromosome may be paired with a deletion or a gene mutation in the same region on the other transmitted chromosome. Thus, the deletion may "unmask" an inherited or de novo gene mutation or deletion [Flipsen-ten Berg et al., 2007; Hochstenbach et al., 2012; Poot and Haaf, 2015]. A case in point is a girl with attention deficit-hyperactivity disorder and cognitive impairments as well as a de novo heterozygous $600-\mathrm{kb}$ deletion in the $16 \mathrm{p} 11.2$ region, which unmasks a heterozygous 2-bp deletion in the CORO1A gene, inherited from the unaffected father [Shiow et al., 2009].

However, upon examination of CNVs within the $16 \mathrm{p} 11.2$ region, additional potentially pathogenic mechanisms of CNVs may become apparent. By array comparative genomic hybridization, Kumar et al. [2008] identified a recurrent 16p11.2 deletion in 4 out of 712 probands $(0.6 \%)$ with ASD and 0 in 837 controls, and Marshall et al. [2008] detected this deletion in 4 out of 427 families with ASD patients and none in 1,652 controls [Kumar et al., 2008; Marshall et al., 2008]. Eichler and Zimmerman [2008] noted that this recurrent CNV contained at least 
25 genes or transcripts, some of which may cause a phenotypic effect if their dosage is altered. Thus, this recurrent CNV likely represents a contiguous gene syndrome.

Candidate genes for the individual phenotypes associated with a CNV can be identified by comparing rare cases with overlapping CNVs. Such dissection of CNVs into regions with shared phenotypes has allowed pinpointing $H N R N P U$ as a gene for epilepsy within the 1q44 region [Caliebe et al., 2010; Ballif et al., 2012; Depienne et al., 2017]. In a cohort of 300 patients with severe early-onset obesity, of whom 143 also had developmental delay, 5 patients with overlapping deletions at chromosome 16p11.2 were found, and 2 in 7,366 controls [Bochukova et al., 2010]. In 3 patients, the deletion cosegregated with severe obesity, while the other 2 patients harbored a larger de novo 16p11.2 deletion, which extended beyond the 593$\mathrm{kb}$ deletion that was previously associated with ASD and intellectual disability. Both of these patients also showed mild developmental delay in addition to severe obesity. All 5 of the 16p11.2 deletions encompassed a 200-kb recurrent $\mathrm{CNV}$ interval, which included $S H 2 B 1$, a gene known to be involved in leptin and insulin signaling [Bachmann-Gagescu et al., 2010]. The 16p11.2 deletion carriers exhibited hyperphagia and severe insulin resistance disproportionate for the degree of obesity. Walters et al. [2010] confirmed these findings on a highly penetrant form of obesity, initially found in 31 patients heterozygous for $16 \mathrm{p} 11.2$ deletions of at least $593 \mathrm{~kb}$, who were investigated because of cognitive deficits among other phenotypes. In GWAS data on 16,053 individuals from 8 European cohorts, 19 similar deletions were identified [Walters et al., 2010]. These deletions were absent from healthy nonobese controls and accounted for $0.7 \%$ of the morbid obesity cases. In 28 cohorts totaling more than 30,000 cases referred for developmental or intellectual delay, 138 carriers of a duplication in region $16 \mathrm{p} 11.2$ of at least $593 \mathrm{~kb}$ with reduced postnatal weight and body mass index were found [Jacquemont et al., 2011]. Thus, the phenotypes of the duplication carriers seem to mirror those of the deletion carriers. The authors suggested that severe obesity and being underweight may have common etiologies, possibly through contrasting effects on energy balance. On the other hand, speech delay, resulting from impairments in the basic mechanisms of speech motor control, and behavioral problems, such as ASD and attention-deficit hyperactivity disorder, are the predominant features in individuals with developmental delay and 16p11.2 deletions and duplications [Rosenfeld et al., 2010; Shinawi et al., 2010; Demopoulos et al., 2018]. Both deletion and duplication carriers show a lowered IQ [Hip- polyte et al., 2016]. While deletion carriers exhibit severe impairments of language and verbal skills, duplication carriers, in contrast, outperform siblings with the same IQ level for their language and verbal abilities [Hippolyte et al., 2016]. These findings underscore the importance of rare variants with a strong effect, albeit they show incomplete penetrance and variable expressivity [Rosenfeld et al., 2010; Shinawi et al., 2010]. The latter may relate to the maternal bias for the origin of deletions $(89.4 \%$ of the cases) and a maternal transmission bias for secondary deletions (69.5\% of the cases) [Duyzend et al., 2016].

To elucidate the complex genotype-phenotype relationships with respect to CNVs of the $16 \mathrm{p} 11.2$ region, mouse models on a C57BL/6N inbred genetic background were created [Arbogast et al., 2016]. Mice carrying a heterozygous deletion ( $\mathrm{Del} /+)$ of the region from the Sult1a1 to the Spn gene, which is homologous to the human 16p11.2 593-kbp locus between breakpoints 4 and 5 (BP4-BP5), showed reduced weight and impaired adipogenesis, hyperactivity, repetitive behaviors, and memory deficits. In contrast, Dup/+ mice showed opposite phenotypes. While the behavioral impact of altered genetic dosage of the $16 \mathrm{p} 11.2$ region was similar in mice and humans (e.g., activity and memory alterations), the metabolic defects were opposite. Adult $\mathrm{Del} /+$ mice are lean in comparison to the obese humans, and the $D u p /+$ mice are overweight in comparison to the underweight humans. Moreover, different patterns of aberrant behavior and structural brain abnormalities were found in engineered mice with different genetic background [Horev et al., 2011; Portman et al., 2014; Arbogast et al., 2016]. Thus, the authors suggested that dosage imbalance at the $16 \mathrm{p} 11.2$ locus perturbs the expression of modifiers outside this CNV, which can modulate the penetrance, expressivity, and direction of effects in both humans and mice [Arbogast et al., 2016].

In humans, the $16 \mathrm{p} 11.2$ region consists of a distal BP2BP3 interval of $220 \mathrm{~kb}$ and a proximal BP4-BP5 interval of $593 \mathrm{~kb}$. The findings in the mouse were extended by investigation of a cohort of 137 unrelated human deletion and reciprocal duplication carriers of the distal with $4 \mathrm{C}$ seqencing, FISH, Hi-C sequencing, and expression analyses for the affected genes [Loviglio et al., 2017]. This study confirmed that $16 \mathrm{p} 11.2$ rearrangements are associated with ASD and the mirror phenotypes of obesity/underweight and macrocephaly/microcephaly. Such phenotypes were previously associated with rearrangements of the nonoverlapping proximal 16p11.2 BP4-BP5 interval of $593 \mathrm{~kb}$. Both CNV-prone regions at $16 \mathrm{p} 11.2$ are reciprocally engaged in complex chromatin looping. To iden-
172
Mol Syndromol 2018;9:171-174 DOI: $10.1159 / 000490845$
Poot 
tify pathways that are perturbed when the dosage of this region is modified, the authors determined the chromosomal contacts of genes mapping within the $16 \mathrm{p} 11.2$ BP4-BP5 interval by chromosome conformation capture. The promoters of 2 of the drivers of the $16 \mathrm{p} 11.2$ phenotype, $M V P$ and $M A P K 3$, engage in long-range chromatin interactions with $P T E N$ and $C H D 1 L$, respectively. The MVP protein regulates the intracellular localization of PTEN, which in turn antagonizes the PI3K/ AKT and Ras/MAPK signaling pathways. Both PTEN germline mutations in humans and targeted inactivation in mice were associated with a macrocephaly/autism syndrome (OMIM 605309). On the other hand, germline mutations in the Ras/MAPK pathway cause a set of syndromes, termed RASopathies, which among other phenotypes affect social interaction. This study demonstrated that expression of members of the PTEN pathway is sensitive to gene dosage at the $16 \mathrm{p} 11.2$ locus. CHD1L, finally, was suggested to be a driver of the phenotypes associated with 1q21.1 CNVs [Mefford et al., 2008].

Taken together, these studies described more accurately the clinical phenotypes associated with recurrent deletions or duplications in the $16 \mathrm{p} 11.2$ region and pinpointed putative candidate genes. Secondly, the results are in agreement with a 2-locus model for clinically relevant recurrent $\mathrm{CNVs}$, albeit the underlying molecular mechanisms are unexpected and novel [Girirajan and Eichler, 2010]. Thirdly, and most importantly, light is shed on phenotypic effects of perturbed chromosomal organization and on the functioning of the genome as a whole. The phenotypic impact of altered patterns of chromosomal contacts is a novel avenue of research meriting further exploration.

Martin Poot

\section{References}

-Arbogast T, Ouagazzal AM, Chevalier C, Kopanitsa M, Afinowi N, et al: Reciprocal effects on neurocognitive and metabolic phenotypes in mouse models of 16p11.2 deletion and duplication syndromes. PLoS Genet 12:e1005709 (2016).

Bachmann-Gagescu R, Mefford HC, Cowan C, Glew GM, Hing AV, et al: Recurrent 200-kb deletions of $16 \mathrm{p} 11.2$ that include the SH2B1 gene are associated with developmental delay and obesity. Genet Med 12:641-647 (2010).

Bailey JA, Eichler EE: Primate segmental duplications: crucibles of evolution, diversity and disease. Nat Rev Genet 7:552-564 (2006).

Ballif BC, Rosenfeld JA, Traylor R, Theisen A, Bader PI, et al: High-resolution array $\mathrm{CGH}$ defines critical regions and candidate genes for microcephaly, abnormalities of the corpus callosum, and seizure phenotypes in patients with microdeletions of 1q43q44. Hum Genet 131:145-156 (2012).

Bochukova EG, Huang N, Keogh J, Henning E, Purmann C, et al: Large, rare chromosomal deletions associated with severe early-onset obesity. Nature 463:666-670 (2010).

- Bucan M, Abrahams BS, Wang K, Glessner JT, Herman EI, et al: Genome-wide analyses of exonic copy number variants in a family based study point to novel autism susceptibility genes. PLoS Genet 5:e1000536 (2009).

Caliebe A, Kroes HY, van der Smagt JJ, MartinSubero JI, Tönnies H, et al: Four patients with speech delay, seizures and variable corpus callosum thickness sharing a $0.440 \mathrm{Mb}$ deletion in region 1q44 containing the HNRPU gene. Eur J Med Genet 53:179-185 (2010).
Campbell CD, Eichler EE: Properties and rates of
germline mutations in humans. Trends Genet
29:575-584 (2013). Cooper GM, Coe BP, Girirajan S, Rosenfeld JA, $\mathrm{Vu} \mathrm{TH}$, et al: A copy number variation morbidity map of developmental delay. Nat Genet 43:838-846 (2011).

Demopoulos C, Kothare H, Mizuiri D, Henderson-Sabes J, Fregeau B, et al: Abnormal speech motor control in individuals with 16 p11.2 deletions. Sci Rep 8:1274 (2018).

Depienne C, Nava C, Keren B, Heide S, Rastetter $A$, et al: Genetic and phenotypic dissection of 1q43q44 microdeletion syndrome and neurodevelopmental phenotypes associated with mutations in ZBTB18 and HNRNPU. Hum Genet 136:463-479 (2017).

Duyzend MH, Nuttle X, Coe BP, Baker C, Nickerson DA, et al: Maternal modifiers and parent-of-origin bias of the autism-associated 16p11.2 CNV. Am J Hum Genet 98:45-57 (2016).

Eichler EE, Zimmerman AW: A hot spot of genetic instability in autism. N Engl J Med 358: 737-739 (2008).

Eichler EE, Johnson ME, Alkan C, Tuzun E, Sahinalp C, et al: Divergent origins and concerted expansion of two segmental duplications on chromosome 16. J Hered 92:462-468 (2001).

Flipsen-ten Berg K, van Hasselt PM, Eleveld MJ, van der Wijst SE, Hol FA, et al: Unmasking of a hemizygous WFS1 gene mutation by a chromosome $4 \mathrm{p}$ deletion of $8.3 \mathrm{Mb}$ in a patient with Wolf-Hirschhorn syndrome. Eur J Hum Genet 15:1132-1138 (2007).

-Girirajan S, Eichler EE: Phenotypic variability and genetic susceptibility to genomic disorders. Hum Mol Genet 19:R176-R187 (2010).
Girirajan S, Rosenfeld JA, Cooper GM, Antonacci F, Siswara P, et al: A recurrent 16p12.1 microdeletion supports a two-hit model for severe developmental delay. Nat Genet 42:203209 (2010).

Hippolyte L, Maillard AM, Rodriguez-Herreros B, Pain A, Martin-Brevet S, et al: The number of genomic copies at the $16 \mathrm{p} 11.2$ locus modulates language, verbal memory, and inhibition. Biol Psychiatry 80:129-139 (2016).

Hochstenbach R, Buizer-Voskamp JE, Vorstman JA, Ophoff RA: Genome arrays for the detection of copy number variations in idiopathic mental retardation, idiopathic generalized epilepsy and neuropsychiatric disorders: lessons for diagnostic workflow and research. Cytogenet Genome Res 135:174-202 (2011).

Hochstenbach R, Poot M, Nijman IJ, Renkens I, Duran KJ, et al: Discovery of variants unmasked by hemizygous deletions. Eur J Hum Genet 20:748-753 (2012).

Horev G, Ellegood J, Lerch JP, Son YEE, Muthuswamy L, et al: Dosage-dependent phenotypes in models of 16p11.2 lesions found in autism. Proc Natl Acad Sci USA 108:17076-17081 (2011).

Itsara A, Wu H, Smith JD, Nickerson DA, Romieu I, et al: De novo rates and selection of large copy number variation. Genome Res 20: 1469-1481 (2010).

Jacquemont S, Reymond A, Zufferey F, Harewood L, Walters RG, et al: Mirror extreme BMI phenotypes associated with gene dosage at the chromosome 16p11.2 locus. Nature 478:97-102 (2011). 
Kumar RA, KaraMohamed S, Sudi J, Conrad DF, Brune C, et al: Recurrent 16p11.2 microdeletions in autism. Hum Mol Genet 17:628-638 (2008).

Loviglio MN, Leleu M, Männik K, Passeggeri M, Giannuzzi G, et al: Chromosomal contacts connect loci associated with autism, BMI and head circumference phenotypes. Mol Psychiatry 22:836-849 (2017).

-Marshall CR, Noor A, Vincent JB, Lionel AC Feuk L, et al: Structural variation of chromosomes in autism spectrum disorder. Am J Hum Genet 82:477-488 (2008).

-Mefford HC, Sharp AJ, Baker C, Itsara A, Jiang Z, et al: Recurrent rearrangements of chromosome 1q21.1 and variable pediatric phenotypes. N Engl J Med 359:1685-1699 (2008).

Poot M: Towards identification of individual etiologies by resolving genomic and biological conundrums in patients with autism spectrum disorders. Mol Syndromol 4:213-226 (2013).

-Poot M, Eleveld MJ, van 't Slot R, Ploos van Amstel HK, Hochstenbach R: Recurrent copy number changes in mentally retarded children harbour genes involved in cellular localization and the glutamate receptor complex. Eur J Hum Genet 18:39-46 (2010).
Poot M, Haaf T: Mechanisms of origin, phenotypic effects and diagnostic implications of complex chromosome rearrangements. Mol Syndromol 6:110-134 (2015).

Portmann T, Yang M, Mao R, Panagiotakos G, Ellegood J, et al: Behavioral abnormalities and circuit defects in the basal ganglia of a mouse model of $16 \mathrm{p} 11.2$ deletion syndrome. Cell Rep 7:1077-1092 (2014).

Rosenfeld JA, Coppinger J, Bejjani BA, Girirajan S, Eichler EE, et al: Speech delays and behavioral problems are the predominant features in individuals with developmental delays and 16 p11.2 microdeletions and microduplications. J Neurodev Disord 2:26-38 (2010).

Salyakina D, Cukier HN, Lee JM, Sacharow S, Nations LD, et al: Copy number variants in extended autism spectrum disorder families reveal candidates potentially involved in autism risk. PLoS One 6:e26049 (2011).

Samonte RV, Eichler EE: Segmental duplications and the evolution of the primate genome. Nat Rev Genet 3:65-72 (2002).
Shinawi M, Liu P, Kang SH, Shen J, Belmont JW, et al: Recurrent reciprocal $16 \mathrm{p} 11.2$ rearrangements associated with global developmental delay, behavioural problems, dysmorphism, epilepsy, and abnormal head size. J Med Genet 47:332-341 (2010).

Shiow LR, Paris K, Akana MC, Cyster JG, Sorensen RU, Puck JM: Severe combined immunodeficiency (SCID) and attention deficit hyperactivity disorder (ADHD) associated with a coronin-1A mutation and a chromosome 16p11.2 deletion. Clin Immunol 131:24-30 (2009).

Stankiewicz P, Lupski JR: Structural variation in the human genome and its role in disease. Annu Rev Med 61:437-455 (2010).

van Daalen E, Kemner C, Verbeek NE, van der Zwaag B, Dijkhuizen T, et al: Social Responsiveness Scale-aided analysis of the clinical impact of copy number variations in autism. Neurogenetics 12:315-323 (2011).

Walters RG, Jacquemont S, Valsesia A, de Smith AJ, Martinet D, et al: A new highly penetrant form of obesity due to deletions on chromosome 16p11.2. Nature 463:671-675 (2010). 